\title{
Drogue Parachute Effects on the Orion Crew Module Stability
}

\author{
Vanessa V. Aubuchon ${ }^{1}$, D. Bruce Owens ${ }^{2}$, and C. Michael Fremaux ${ }^{3}$ \\ NASA Langley Research Center, Hampton, Virginia, 23681
}

\begin{abstract}
A forced oscillation test of the Orion Crew Module (CM) was conducted in the Langley 20-Foot Vertical Spin Tunnel. The objective of the test was to quantify the rate damping characteristics of the CM-drogue chute system. Numerous configurations were tested to measure the influence of the chutes on the CM dynamic aerodynamics and, conversely, the influence of the CM on drogue performance. Results show that the CM-drogue system is well-damped at all combinations of frequency, amplitude, and Strouhal number. The wake of the CM significantly reduces the drogue chute riser line force, and the drogues have little upstream influence on the CM aerodynamics. These results are being used to improve simulation model fidelity of CM flight with drogues deployed, which has been identified by the project as key to a successful Orion Critical Design Review.
\end{abstract}

\section{Nomenclature}

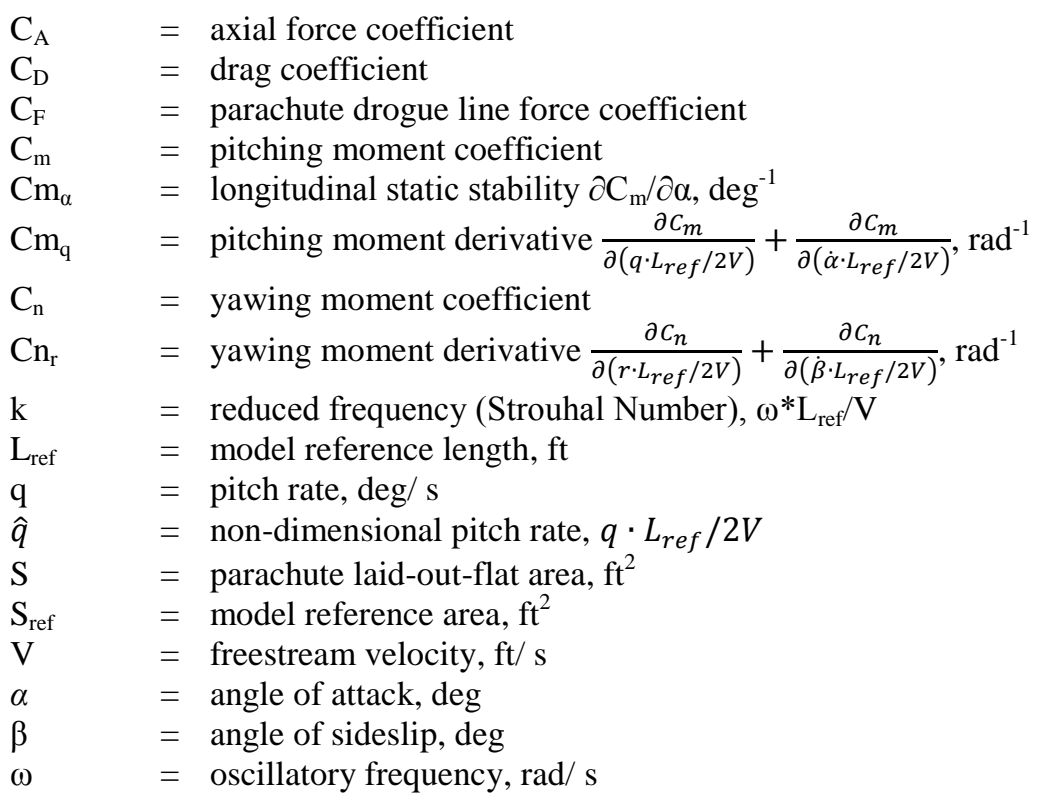

\section{Introduction}

$\mathrm{N}$ ASA'S plan for human space exploration calls for a long term exploration to an asteroid and eventually to Mars. These goals require the development of a new spacecraft known as the Orion Multi-Purpose Crew Vehicle (MPCV), which is based on the recently cancelled Crew Exploration Vehicle (CEV) design requirements for traveling beyond Low Earth Orbit ${ }^{1}$. The Orion MPCV is based on a design similar to the Apollo program's Command and Service Modules and is composed of four main elements: the Launch Abort System, the Crew Module, the Service Module, and the Spacecraft Adapter as shown in Fig. $1^{2}$. The Launch Abort System (LAS) provides a reliable abort capability for aborts that occur within the atmosphere. The Crew Module (CM) provides a

\footnotetext{
${ }^{1}$ Aerospace Engineer, Flight Dynamics Branch, Mail Stop 308, Senior Member.

${ }^{2}$ Aerospace Engineer, Flight Dynamics Branch, Mail Stop 308, Associate Fellow.

${ }^{3}$ Head, Flight Dynamics Branch, Mail Stop 308, Senior Member.
} 
safe habitable volume for the crew during launch, spaceflight, and return through the atmosphere. The Service Module (SM) provides additional resources necessary to support the primary mission, including power and maneuvering capability. The SM is also used to provide abort capability for exoatmospheric aborts. The Spacecraft Adapter provides the interface between the spacecraft and the Crew Launch Vehicle.

The drogue parachutes serve to not only slow down the CM after reentering the Earth's atmosphere but to stabilize the CM to enable proper main parachute deployment and inflation. Recent Monte Carlo simulations

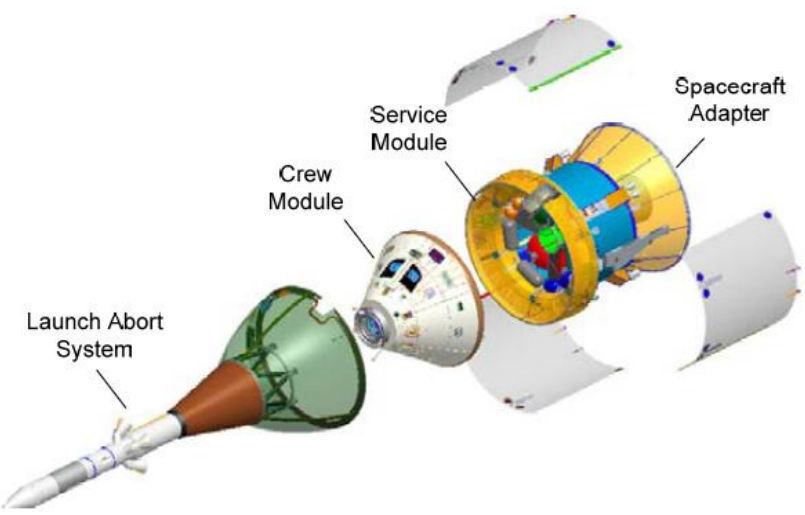

Figure 1. Orion Multi-Purpose Crew Vehicle. indicated that, under certain dispersed conditions, the dynamics of the CM while flying with the drogues fully deployed result in unacceptable levels of pitching and yawing motion. Full-scale flight tests, including Orion's Pad Abort 1 and the Apollo missions, as well as previous dynamically-scaled model tests in the Langley 20-Foot Vertical Spin Tunnel (VST) ${ }^{3}$ did not indicate that the dynamics would be as severe as predicted by simulation. A concern is that the simulations are not accurately calculating the total system damping. In order to improve simulation model fidelity of CM flight with drogues deployed, a dynamic aero test of the CM was conducted in the VST. The objective of this test was to quantify the rate damping characteristics (in the form of dynamic derivatives) of the CM-drogue chute system using the forced oscillation technique. It is believed that this is the first time since the Apollo program that dynamic aerodynamics of an integrated capsule-drogue system have been measured directly.

The unique combination of dynamic testing capabilities and specialized technician skills at the VST were used to quickly adapt an existing model and parachutes for this test. Numerous configurations were tested to measure the

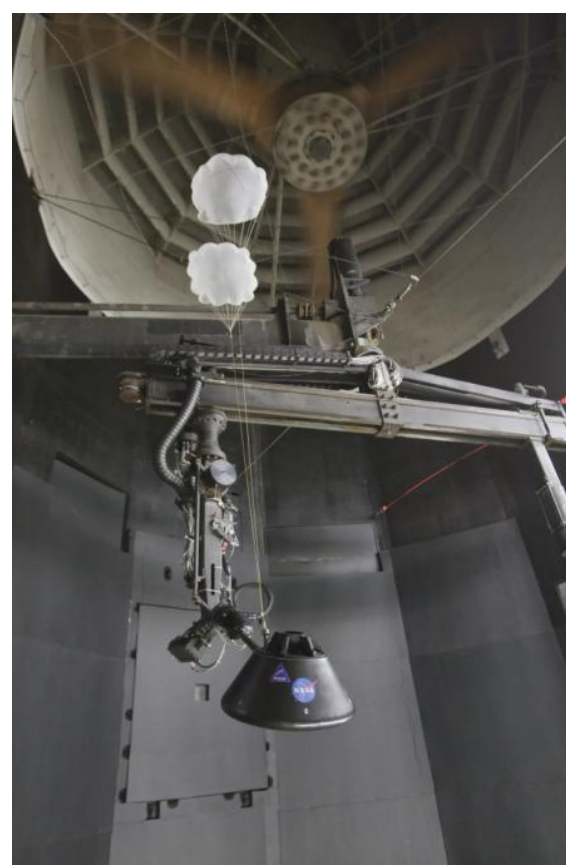

Figure 2. Orion Crew Module with drogue parachutes in Langley 20Foot Vertical Spin Tunnel. influence of the chutes on the CM dynamic aerodynamics, and, conversely, the influence of the $\mathrm{CM}$ on the drogue performance. Both nominal two-drogue and drogue-out configurations were analyzed. Aerodynamic damping measurements were made using a six-component strain gage balance, whereas an in-line load cell was used to independently measure drogue riser line force.

\section{Test Setup}

The experimental wind tunnel test was performed in the NASA Langley 20-Foot Vertical Spin Tunnel. The VST is a low speed, annular return tunnel that operates at nominal atmospheric conditions. The closed, 12 -sided test section is 20 feet across and 25 feet high. The VST has provided key subsonic, dynamic stability data for many atmospheric entry vehicles, including the Pioneer Venus, Stardust, and Mars Sample Return planetary probes and the Mercury, Gemini, and Apollo space capsules. The VST has more recently been utilized to assess subsonic dynamic stability of the Orion LAS, CM, and drogue parachute performance. The tunnel's rotary balance system has a forced oscillation capability that is used to measure body axis rate damping characteristics.

A $1 / 16^{\text {th }}$-scale CM was modified from a free-flight model $^{3,5}$ to accept 6-component balance hardware. The model was built using an automated polycarbonate fabrication system in the NASA Langley (LaRC) rapid prototyping lab. The model with drogues attached is shown in Fig. 2. The model reference length and reference area used to compute aerodynamic coefficients are based on capsule diameter. 


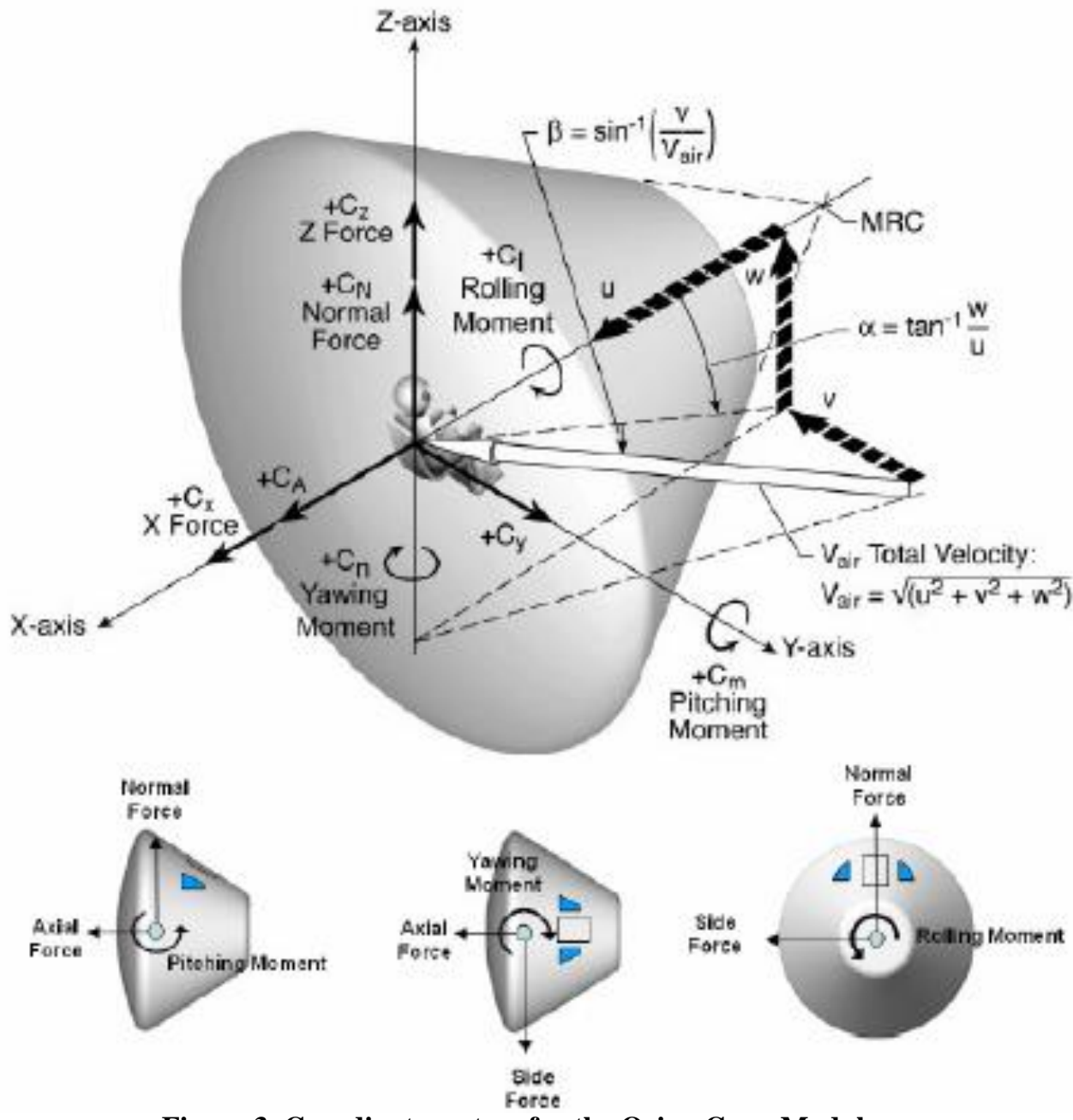

Figure 3. Coordinate system for the Orion Crew Module.

The parachutes used for this test were acquired from an inventory at the VST that is used for airplane spinrecovery and entry vehicle drogue parachute testing. The 18-inch diameter flat, circular parachutes have a full scale drag area $\left(\mathrm{C}_{\mathrm{D}} \mathrm{S}\right)$ of $221 \mathrm{ft}^{2}$ based on a $\mathrm{C}_{\mathrm{D}}$ of 0.55 , and are constructed of high permeability nylon that results in good stability and a near-zero trim angle. The model towline length - defined as the length from the attachment point to the canopy skirt - was 62.5 inches (1,000 inches full-scale). The parachute towlines were attached to the 0 -degree

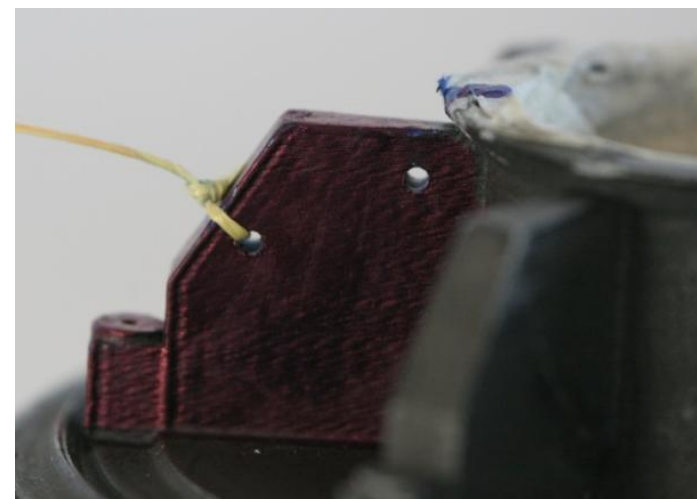

Figure 4. "Down and out" drogue parachute attachment point on the "zero degree" gusset. gusset, or the gusset aligned with the $+\mathrm{Z}$ body axis as shown in Fig. 3, at the "down and out" attachment point, shown in Fig. 4.

A six-component, 1.110-inch diameter strain gage balance was used to measure forces and moments on the model. During the rapid model modification from free-flight to a captive configuration, a compromise was made to expose a portion of the balance to the flow. This exposed portion was covered with a thin membrane (highly flexible "dental dam" material). No significant effect was noted in the electrical "zeros" due to the membrane. The balance was mounted on the axis of rotation at the center of gravity (CG) location. Since the CG is offset in the $-\mathrm{Z}$ direction, internal model hardware allowed for the balance to be shifted to the correct CG location within the model when changing from pitch to yaw 
configurations, leaving one sting entry in the model.

A position potentiometer was used to measure model position for the forced oscillation technique. The model sting was rotated to set the model at the desired angle of attack and then oscillated about that point to obtain force and moment time history data necessary to calculate damping derivatives. Drogue line forces were measured with an Omega in-line load cell (model LCFD-10). The load cell has a load limit of 10 pounds and a diameter of 0.75 inches and weighs 1.48 ounces.

In order to assess $\mathrm{CM}$ forces and moments under the influence of the drogues, a separate "drogue sting" was fabricated by VST staff to attach the drogues at the correct location over the CM for both pitch and yaw motions in order to assess the possible influence of the drogues on $\mathrm{CM}$ aerodynamics. This drogue sting rotated with the $\mathrm{CM}$ for the forced oscillation technique, allowing the drogue attachment point to remain at the proper location over the CM. A conceptual drawing of the pitch and yaw configurations for this drogue sting is shown in Fig. 5. This sting with drogues attached in the pitch configuration is pictured in Fig. 6. Also seen in Fig. 6 is the Omega load cell attached to the drogue sting.
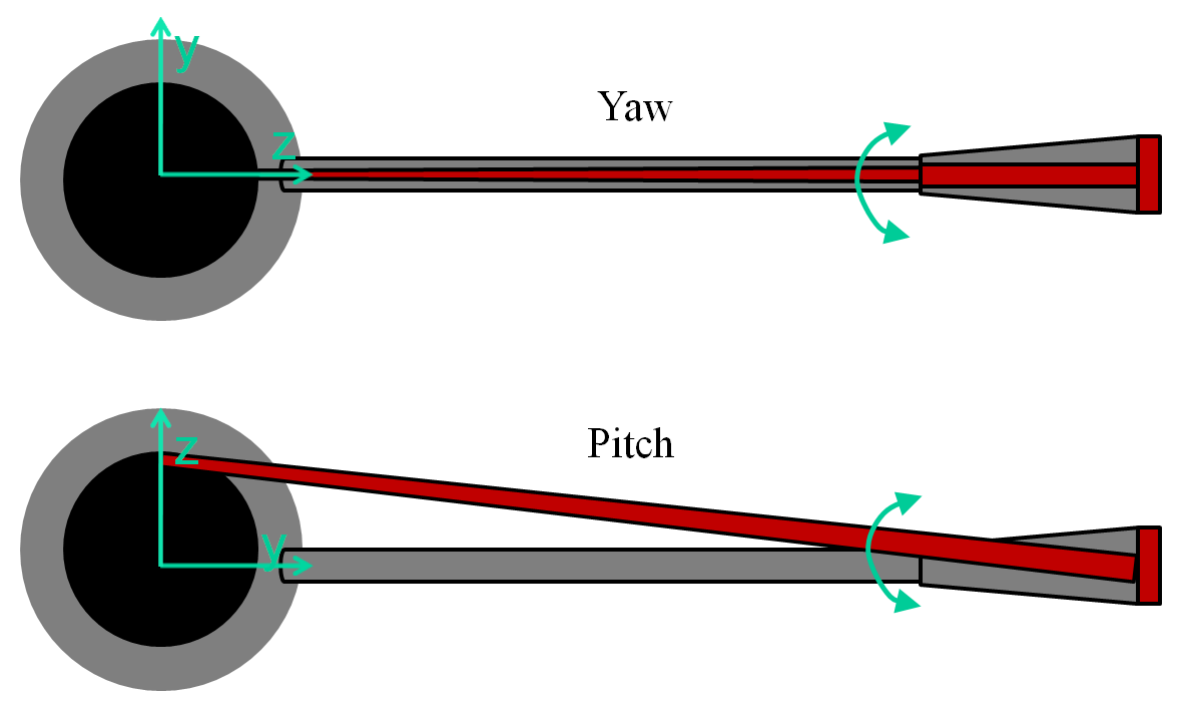

Figure 5. Pitch and yaw drogue sting configurations (red) and model sting (grey).

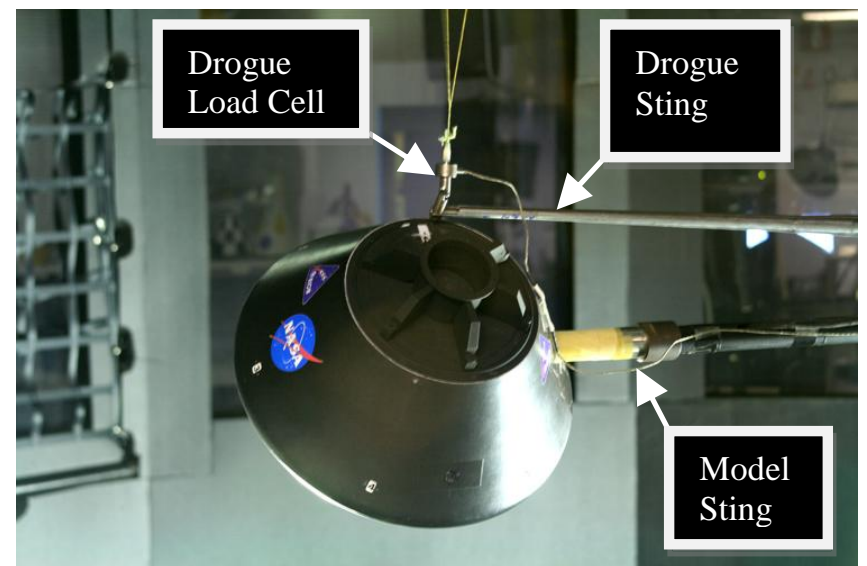

Figure 6. Crew Module model with drogues attached to drogue sting in pitch configuration. 


\section{Test Outline and Objectives}

The purpose of this wind tunnel test was to determine the combined, as well as individual, components of the dynamic damping of the CM-drogue system. The data obtained from this wind tunnel test were used to assess the effectiveness of the drogue chutes in providing rate damping for the $\mathrm{CM}$ - both static and dynamic, including the effect of sideslip, Strouhal number, and non-dimensional angular rate. The induced effect of drogues on CM aerodynamics was also assessed. In addition, the test provided data to assess the static and dynamic effects of one drogue out.

The majority of the test was focused on measuring the pitching moment, but some data were collected for the yaw configuration as well, and is presented in the Results section of this paper. Test data were gathered for the heatshield-forward condition, which is the orientation that the vehicle descends through the atmosphere. Strouhal number and angular rates for the forced oscillation testing were chosen based on dynamics observed in model freeflight tests of the CM with drogues ${ }^{5}$.

The majority of the wind tunnel test was conducted at a dynamic pressure of $3 \mathrm{psf}$ and a Reynolds number of 310,000 based on the CM diameter. A small portion of the test was performed at a dynamic pressure of $1.5 \mathrm{psf}$ in order to achieve desired Strouhal number and non-dimensional angular rate variations. The Reynolds number for this test was low, and there is some Reynolds number effect on dynamic derivatives as discussed in Ref. 6. However, as the first step in correctly modeling the flight dynamics of the CM-drogue system, the data gathered in this test will be used to aide in reproducing similar dynamics in a simulation as was seen in free flight tests in the VST - utilizing the same tunnel, test conditions, model, and parachutes. This allows a rapid, inexpensive method of potentially identifying a simulation modeling problem that may also apply at higher Reynolds numbers. Utilizing the VST in this manner also allows for an inexpensive method of identifying challenges and best practices for working with the drogue parachutes in a more expensive wind tunnel should the need arise.

The angle-of-attack range tested was $100^{\circ}$ to $220^{\circ}$. Angle of attack of $180^{\circ}$ is the heatshield forward attitude for the CM. Sideslip angle was varied from $-40^{\circ}$ to $40^{\circ}$ at various angles of attack. Sinusoidal motion with amplitudes of up to $\pm 40^{\circ}$ and frequencies of up to $2 \mathrm{~Hz}$ was used for the forced oscillation technique.

Seven model configurations were tested and are described in Table 1. These seven configurations provided data to assess many important effects, such as the interference effect of the drogue sting by comparing configuration 1 with 2; induced influence of drogues on CM aerodynamics by comparing configuration 2 with 4; and effect of drogues on total system damping by comparing configuration 1 with 6 (or 2 with 3). The drogue riser line force without the CM wake was measured with configuration 5. Configuration 7 was used to model a drogue-out case and to obtain additional data to aide in validating the simulation's modeling of two drogues as a single drogue. Figures 7 and 8 show the $\mathrm{CM}$ and drogues with and without the drogue sting, respectively.

Table 1. Model configurations tested.

\begin{tabular}{|lll|}
\hline Configuration & Description & Purpose \\
\hline $\mathbf{2}$ & CM alone & $\begin{array}{l}\text { Baseline for comparing CM dynamics with and } \\
\text { without the drogues }\end{array}$ \\
\hline $\mathbf{3}$ & CM alone with the drogue sting & Aerodynamic effect of the drogue sting on CM \\
\hline $\mathbf{4}$ & $\begin{array}{l}\text { Two fully-deployed drogues } \\
\text { attached to CM plus drogue sting }\end{array}$ & $\begin{array}{l}\text { Total system static and dynamic aerodynamics with } \\
\text { drogue sting in place }\end{array}$ \\
\hline $\mathbf{5}$ & $\begin{array}{l}\text { Two fully-deployed drogues } \\
\text { attached to drogue sting }\end{array}$ & $\begin{array}{l}\text { CM forces and moments under the aerodynamic } \\
\text { influence of the drogues }\end{array}$ \\
\hline $\mathbf{6}$ & $\begin{array}{l}\text { Two fully-deployed drogues alone } \\
\text { mounted to the drogue sting }\end{array}$ & Drogues alone riser line forces \\
\hline $\mathbf{7}$ & $\begin{array}{l}\text { Two fully-deployed drogues } \\
\text { attached to CM with no drogue } \\
\text { sting }\end{array}$ & $\begin{array}{l}\text { Total system static and dynamic aerodynamics without } \\
\text { the drogue sting }\end{array}$ \\
\hline $\begin{array}{l}\text { Single fully-deployed drogue } \\
\text { attached to CM with no drogue } \\
\text { sting }\end{array}$ & $\begin{array}{l}\text { Direct analogy to current two-body simulations of the } \\
\text { CM and drogues, which model two drogues as a single } \\
\text { drogue }\end{array}$ \\
\hline
\end{tabular}




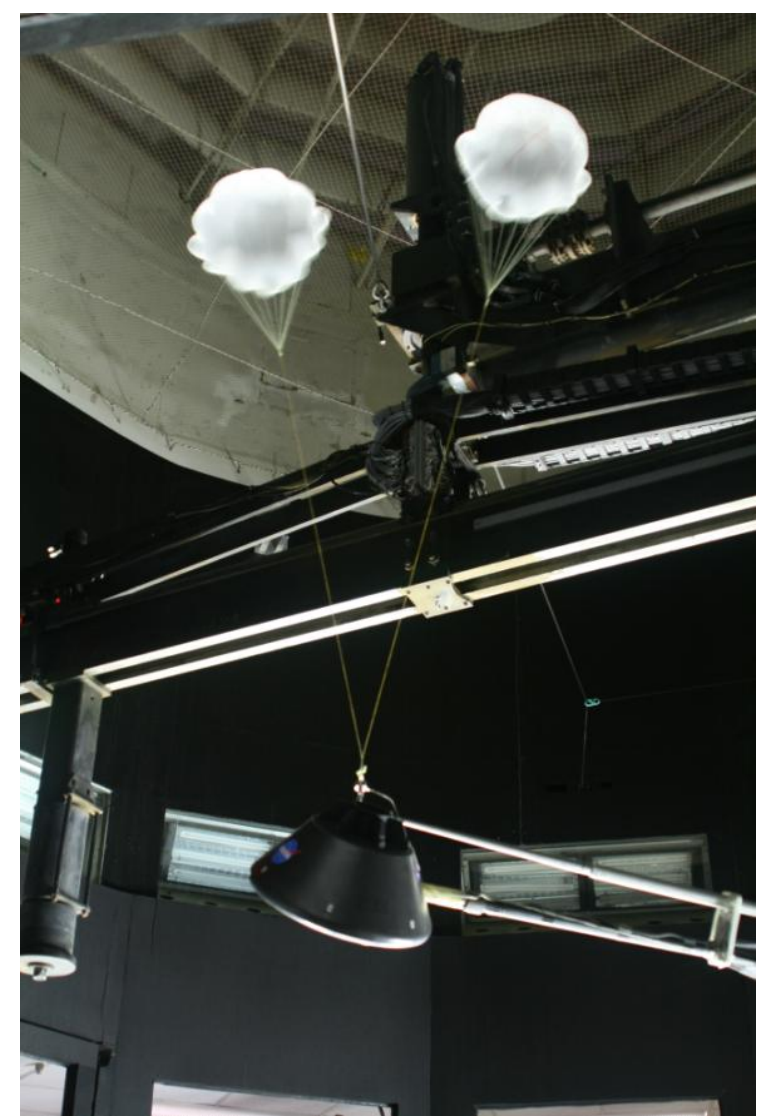

Figure 7. Crew Module with drogue sting.

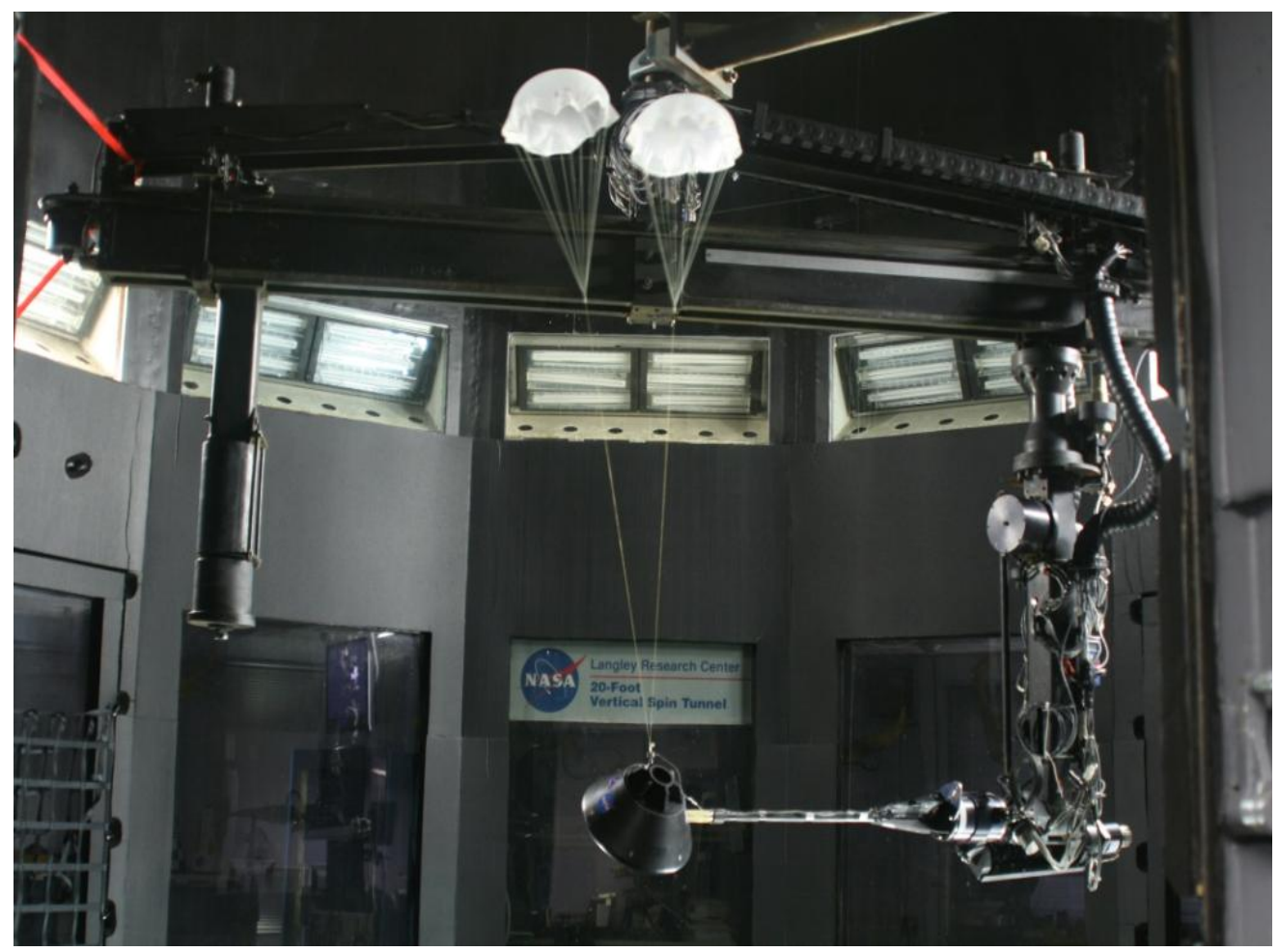

Figure 8. Crew Module without drogue sting. 


\section{Results}

Other than providing additional drag, a major purpose of the drogue chutes is to stabilize the CM to enable proper main parachute deployment and inflation. The results from this wind tunnel test show that the drogue chutes are achieving this task. The degree to which they are achieving this task is currently in question based on conflicting data from flight tests and dispersed simulation results. The results discussed below focus on quantifying the static stability, dynamic stability, and drogue chute drag reduction due to $\mathrm{CM}$ wake. The CM static and dynamic aerodynamics are discussed in detail in References 7 and 8.

\section{A. Longitudinal Static Aerodynamic Characteristics}

Figure 9 shows the pitching moment at a range of angle of attack values around the heatshield-forward attitude for the different configurations tested. Comparing the CM Alone and CM with Two Drogues configurations shows a significant increase in static stability $\mathrm{Cm}_{\alpha}$ (i.e., slope of the linearized curves in Fig. 9) due to the restoring moment of the drogues. The drogue chutes also cause the trim angle of attack to move from about $167^{\circ}$ to $148^{\circ}$ due to their laterally-offset attachment point.

The effect of one drogue out is also shown in Fig. 9. The drogue-out case still provides considerable static stability compared to the CM alone.

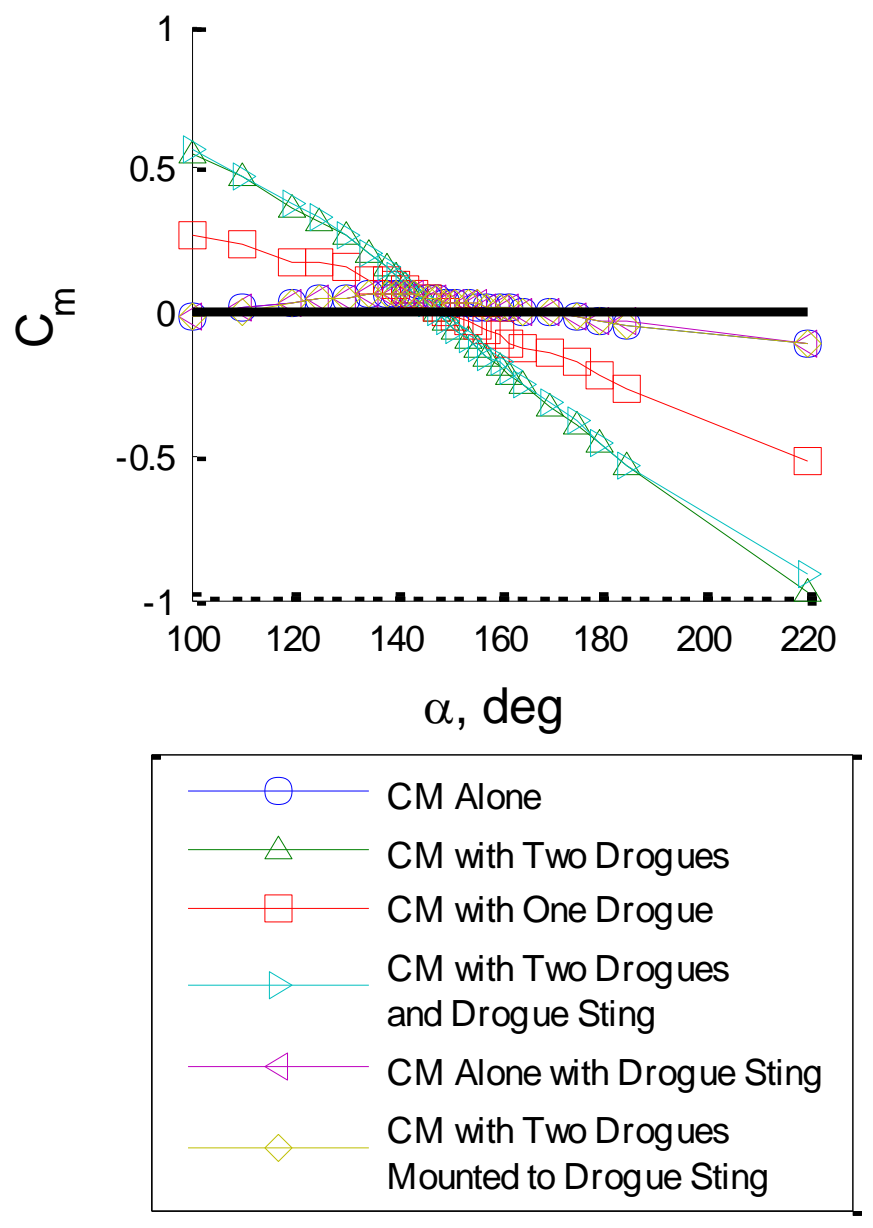

Figure 9. Static stability for six tested configurations. 


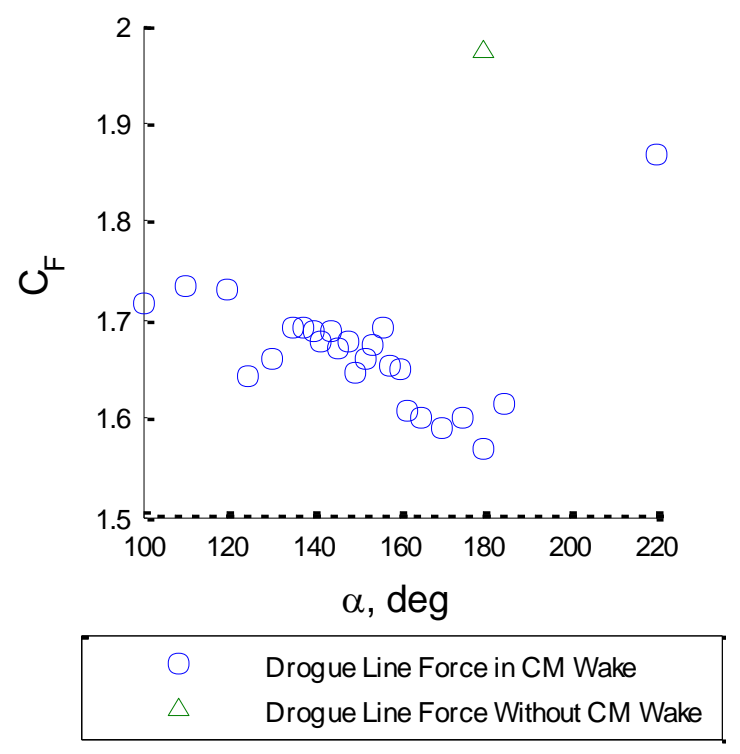

Figure 10. The drogue force versus CM angle of attack.

The drogue line force coefficient (nondimensionalized with CM parameters) is plotted in Fig. 10. Recall the drogue chute attachment point is on the $+\mathrm{Z}$ axis. Therefore, the drogues see a less turbulent flow for an angle of attack greater than $180^{\circ}$ than for less than $180^{\circ}$. In other words, the wake deficit (reduced dynamic pressure approaching the chutes compared to freestream) at the chutes is not symmetric about a CM angle of attack of $180^{\circ}$. Fig. 10 shows this trend, as well as the drogue line force without the CM wake. The CM wake causes a maximum drag reduction of approximately $20 \%$. This is half of the value predicted by NASA Johnson Space Center's Applied Aeroscience and Computation Fluid Dynamics Branch, and almost double the 12.4\% drag reduction described in Ref. 9 for the $\mathrm{CM}$ at $20^{\circ}$ angle of attack ( $7.3 \%$ for the $\mathrm{CM}$ in the heatshield forward attitude).

\section{B. Pitch Damping Characteristics}

The forced oscillation data were reduced using the "single point" method. $\mathrm{Cm}_{\mathrm{q}}$ is calculated by differencing the measured pitching moment at the points of maximum and minimum rate on the averaged hysteresis loop and dividing by the non-dimensional pitch rate. The forced oscillation technique, including data reduction, are described in detail in Ref. 10. Stable damping is indicated by negative values of $\mathrm{Cm}_{\mathrm{q}}$.

Figure 11 compares the damping for the $\mathrm{CM}$ without drogues and the $\mathrm{CM}$ with two fully-deployed drogues. The data plotted are for a frequency of $2 \mathrm{~Hz}$ and amplitude of $10^{\circ}$, or Strouhal number of 0.125 and non-dimensional angular rate of 0.022. The CM-drogue system exhibited this frequency of motion in the earlier free-flight test in the VST. A few calculated Cmq values in Fig. 11 do not appear to follow the damping trend and are currently under investigation. There are several possible explanations for this phenomenon, including sensitivity to the data reduction method and repeatability concerns due to the unsteady nature of the drogues. The drogues have a relatively constant damping effect from an angle of attack of $144^{\circ}$ to $180^{\circ}$. Below $144^{\circ}$, the drogues significantly increase their damping capability. This result correlates with the trend of drogue line force with angle of attack (as shown earlier in Fig. 10). 


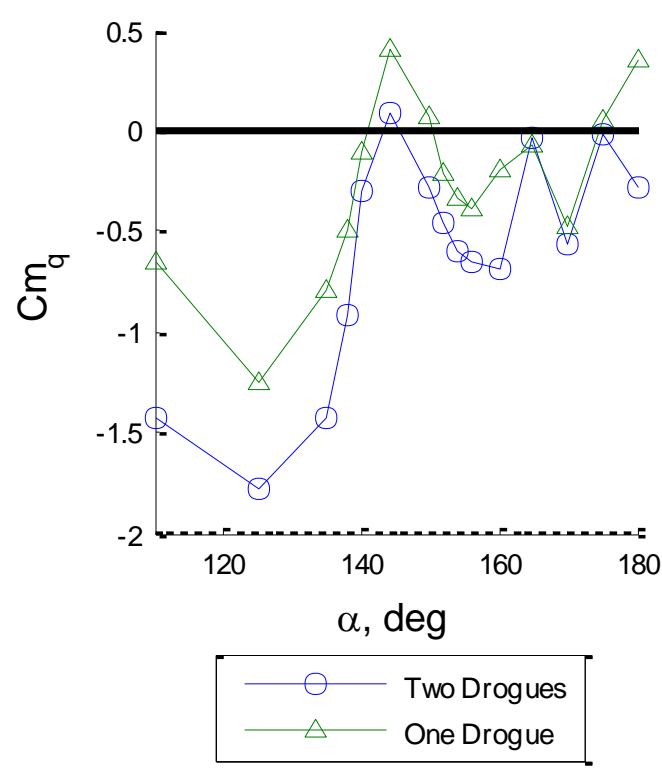

Figure 12. Effect of Drogue Out $(k=0.045, \hat{q}$ $=0.016$ ).

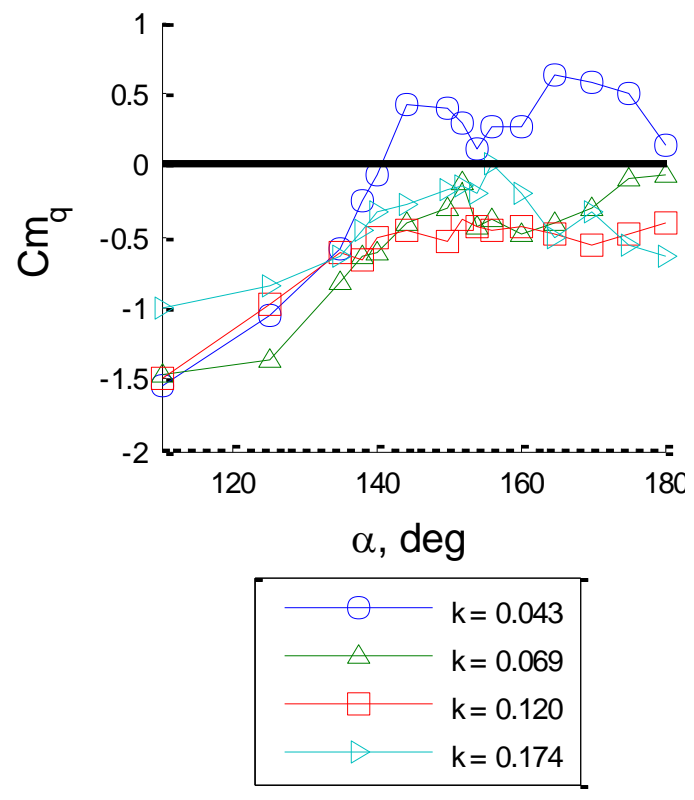

Figure 13. Effect of Strouhal number on damping with drogues $(\hat{q}=\mathbf{0 . 0 3 0})$.
Figure 12 shows the effect of one drogue out on dynamic pitch stability. The data compared were computed from oscillations with a frequency of $0.5 \mathrm{~Hz}$ and amplitude of 20 degrees, or Strouhal number of 0.045 and non-dimensional angular rate of $0.016 . \mathrm{Cm}_{\mathrm{q}}$ decreases for one drogue versus two, indicating the drag force from two drogues is more stabilizing to the CM-drogue system than one drogue as expected.

The effect of Strouhal number on damping of the CMdrogue system is shown in Fig. 13. The non-dimensional angular rate was held constant at 0.030 . A negligible effect is seen for Strouhal numbers (k) between 0.069 and 0.174 . For a Strouhal number of 0.043 , damping becomes unstable for the angle-of-attack range between $140^{\circ}$ and $180^{\circ}$. The effect of angular rate $(\hat{q})$ on damping of the CM-drogue system is shown in Fig. 14. Strouhal number was held constant at 0.044 . In general, the damping derivative increases in the positive direction (becomes less stable) as the angular rate increases. The frequencies and amplitudes chosen to capture the effects of Strouhal number and angular rate were limited by the capability of the forced oscillation rig. It should be noted, however, that the rig was capable of oscillating the model at the desired frequency to match free-flight motion in earlier VST tests.

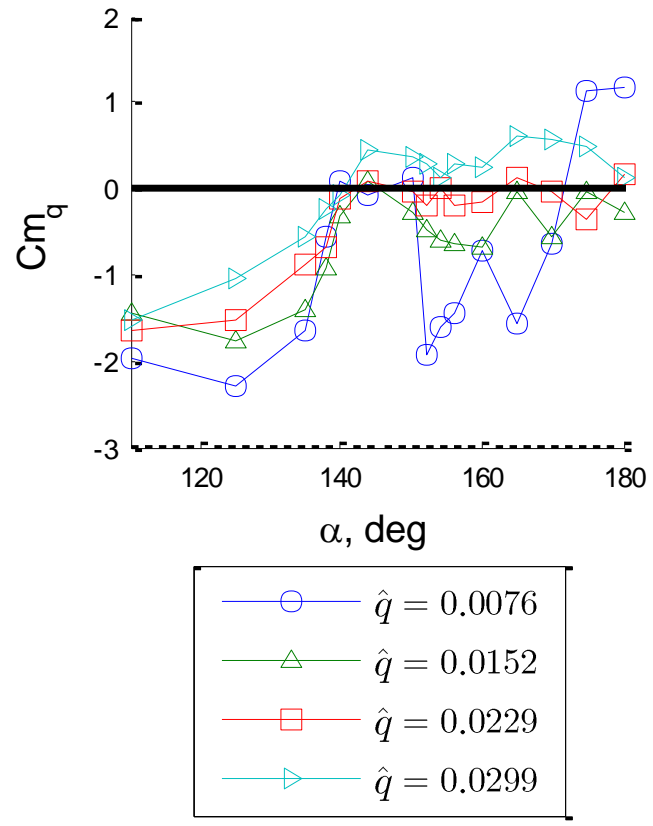

Figure 14. Effect of angular rate on damping with drogues $(k=0.044)$. 


\section{Influence of Chutes on CM Aerodynamics}

Since the drogue sting is an additional object inserted into the flow between the CM and the drogues, there was some concern that the drag produced by the drogues would be affected. Comparing the CM with Two Drogues and CM with Two Drogues and Drogue Sting configurations reveals that the drogue sting had a negligible effect on both static and dynamic forces and moments, as shown in Fig. 9 and Fig. 11.

Also confirmed in Fig. 9 and Fig. 11 is the hypothesis that the drogues do not induce significant aerodynamic effects on the CM. Since the data indicate similar aerodynamic forces and moments for the CM Alone with Drogue Sting and CM with Two Drogues Mounted to Drogue Sting configurations, there is no evidence (at the resolution of the instruments used in this test) of the drogue parachutes inducing upstream aerodynamic effects on the CM.

\section{Yaw Damping Characteristics}

A non-zero sideslip angle of $10^{\circ}$ causes an insignificant change in drogue line force, shown in Fig. 15, and total system damping, shown in Fig. 16. Due to the unsteady nature of the drogue parachutes in the CM wake, these values are within the repeatability bounds of the CM-drogue system.

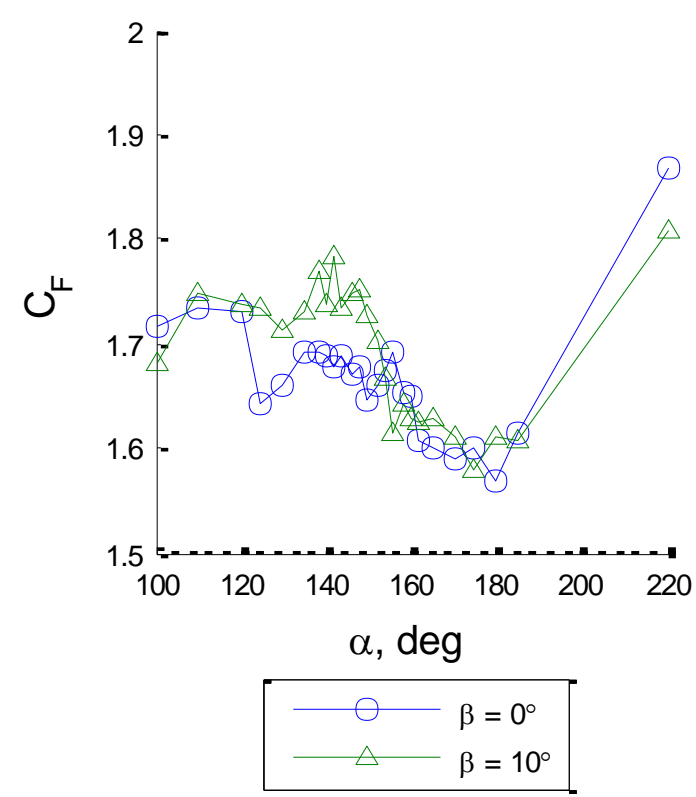

Figure 15. Effect of sideslip on drogue line force.

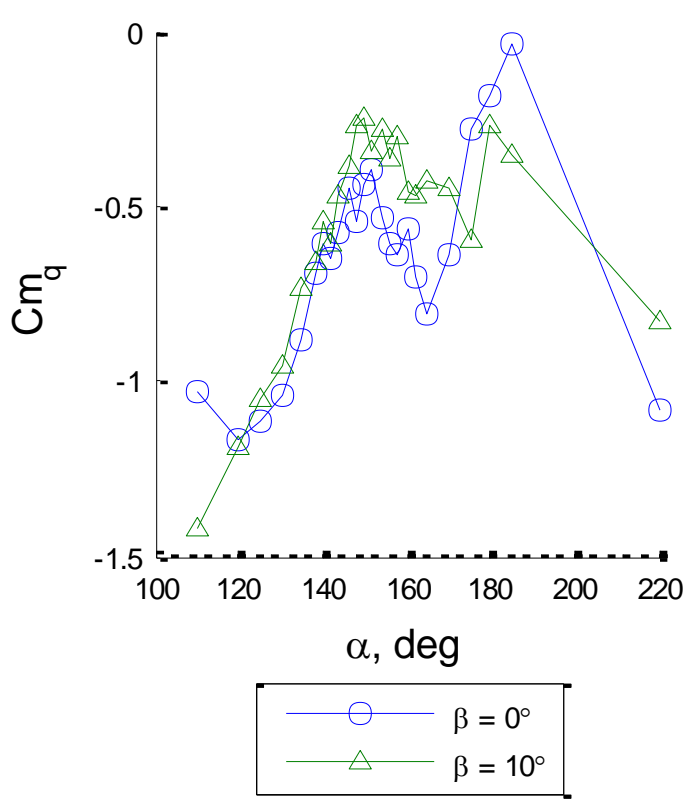

Figure 16. Effect of sideslip on longitudinal dynamic stability. 
Figure 17 shows the effect of angle of attack on yaw damping where little effect is noted. For sideslip angles near $0^{\circ}$, damping is less stabilizing at the minimum angle of attack of $130^{\circ}$. A comparison of $\mathrm{Cn}_{\mathrm{r}}\left(\right.$ at $\left.\alpha=180^{\circ}\right)$ to $\mathrm{Cm}_{\mathrm{q}}$ (at $\beta$ of $\left.0^{\circ}\right)$ is shown in Fig. 18. Pitch and yaw damping values are similar near trim attitude $\left(\beta=0^{\circ}, \alpha=148^{\circ}\right)$. However, pitch damping dramatically increases as angle of attack departs from trim, whereas yaw damping only slightly increases.

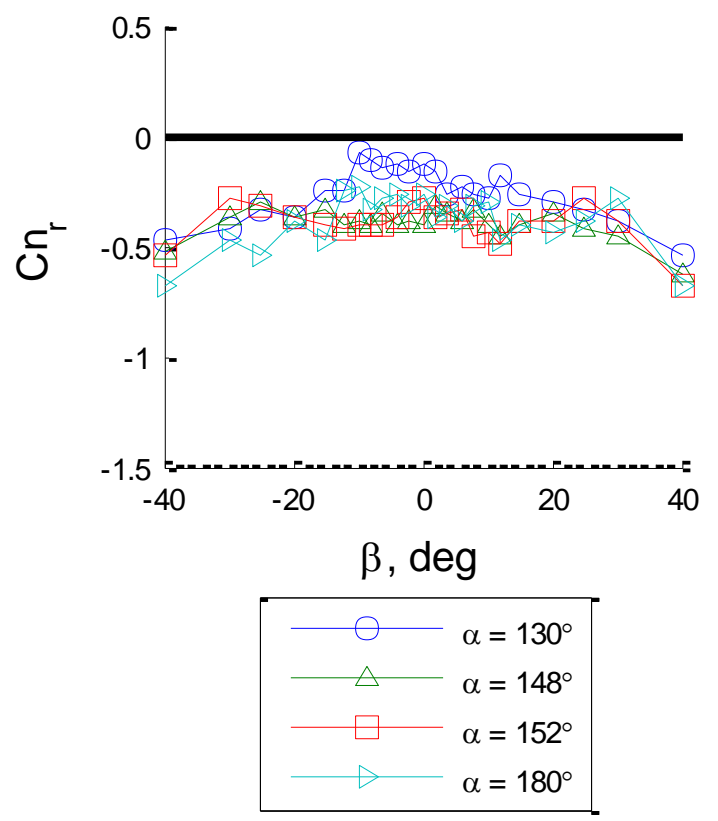

Figure 17. Effect of angle of attack on yaw damping.

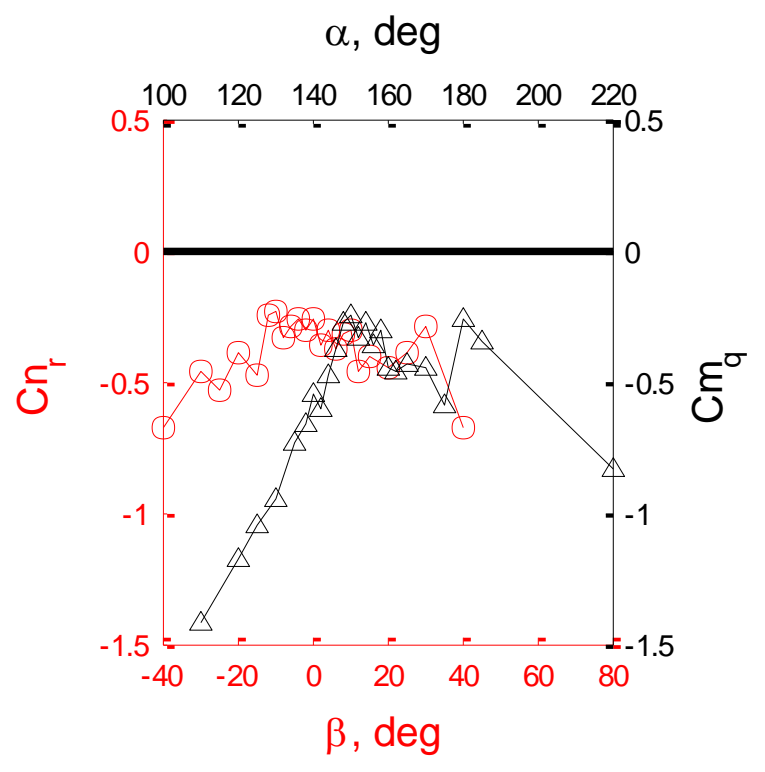

Figure 18. Yaw damping at $180^{\circ}$ angle of attack compared to pitch damping at $0^{\circ}$ sideslip angle.

\section{Summary and Conclusions}

Other than providing additional drag, a major use of the drogue parachutes is to stabilize the CM to enable proper main parachute deployment and inflation. The results from this wind tunnel test show that the drogue chutes are achieving this task. The degree to which they are achieving this task is currently in question based on conflicting data from flight tests and dispersed simulation results. The objective of this test was to quantify the rate damping characteristics - in the form of dynamic derivatives - of the CM-drogue chute system using the forced oscillation technique. It is believed that this is the first time since the Apollo program that dynamic aerodynamics of an integrated capsule-drogue system have been measured directly.

The unique combination of dynamic testing capabilities and specialized technician skills at the VST were used to rapidly adapt an existing free-flight model and parachutes for this test. An additional sting was also fabricated on which the drogue parachutes were independently attached and able to oscillate with the $\mathrm{CM}$, maintaining the proper drogue attachment location. Damping measurements were made using a six-component strain gage balance, whereas an in-line load cell was used to independently measure drogue riser line force. Numerous configurations were tested to measure the combined, as well as individual, components of the dynamic damping of the CM-drogue system. The data obtained from this wind tunnel test were used to assess the influence of the chutes on the CM dynamic aerodynamics, and conversely, the influence of the CM on drogue performance. Both the nominal twodrogue system and one drogue-out configurations were analyzed.

This wind tunnel test was conducted at a Reynolds number of 310,000 based on the CM diameter. As the first step in correctly modeling the flight dynamics of the CM-drogue system, the data gathered in this test will be used to aide in reproducing similar dynamics in a simulation as was seen in free flight tests in the VST - utilizing the same tunnel, test conditions, model, and parachutes. This allows a rapid, inexpensive method of potentially identifying a simulation modeling problem that may also apply at higher Reynolds numbers. Utilizing the VST in this manner also allows for an inexpensive method of identifying challenges and best practices for working with the drogue parachutes in a more expensive wind tunnel should the need arise. 
The results documented in this paper focus on quantifying the static stability, dynamic stability, and drogue chute drag reduction due to $\mathrm{CM}$ wake. Results show that the CM-drogue system is well damped at all combinations of frequency, amplitude, and Strouhal number.

- The drogues have a relatively constant damping effect from an angle of attack of $144^{\circ}$ to $180^{\circ}$. Below $144^{\circ}$, the drogues significantly increase their damping capability. This result correlates with the trend of drogue line force with angle of attack.

- $\mathrm{Cm}_{\mathrm{q}}$ decreases from one drogue versus two, as expected.

- The lowest Strouhal number (0.043) variation showed unstable damping for the angle-of-attack range between $140^{\circ}$ and $180^{\circ}$.

- In general, the damping derivative increases in the positive direction (becomes less stable) as the angular rate increases.

- A non-zero sideslip angle of $10^{\circ}$ causes an insignificant change in drogue line force and total system damping.

- Pitch and yaw damping values are similar near trim attitude, but pitch damping dramatically increases as angle of attack departs from trim, whereas yaw damping only slightly increases.

Additionally, it was seen that the wake of the CM reduces the drogue riser line force due to the reduced wake dynamic pressure (at the towline length tested) by approximately $20 \%$, and the drogues have little upstream influence on CM aerodynamics (either statically or dynamically). These results are currently being used to improve simulation model fidelity of CM flight with drogues deployed, which has been identified by the project as a key issue for a successful Orion Critical Design Review (CDR).

\section{Acknowledgments}

The authors would like to thank Sue Grafton, Earl Harris, Clinton Duncan, Wes O’Neal, and Lee Pollard of the Langley Flight Dynamics Branch for their technical support of the wind tunnel test.

\section{References}

1"'Exploration Systems Architecture Study Final Report," NASA TM-2005-214062, Nov. 2005.

2"'Crew Exploration Vehicle Architecture Design Document," NASA CEV Document Number: CxP-72140, Jan. 2007.

${ }^{3}$ Fremaux, C. M.; "Final Report for CEV Test 48-CD: Low Subsonic Dynamic Stability Test of the Orion Crew Module," NASA CEV Aerosciences Program Document Number: EG-CAP-08-122, June 2008.

4"'Data Report for Low Speed Wind Tunnel Tests of a 0.10-Scale Apollo Model (FDC-1) to Determine Dynamic Stability Characteristics of the Command Module and Drogue Parachute Combination," NASA CR-116641, August 1963.

${ }^{5}$ Hahne, D.E., Fremaux, C.M., "Low-Speed Flight Dynamic Tests and Analysis of the Orion Crew Module Drogue Parachute System," AIAA-2008-6391, Aug. 2008.

${ }^{6}$ Owens, D.B. and Tomek, D.; "18-CD Subsonic-Transonic Crew Module Dynamic Stability Test in the NASA LaRC Transonic Dynamics Tunnel," NASA CEV Aerosciences Program Document Number: EG-CEV-06-23, Feb. 2009.

${ }^{7}$ Murphy, K.J., Bibb, K.L., Gregory, J.B., Rhode, M.N., Owens, D.B., Chan, D.T., Walker, E.L., Bell, J.H., Wilson, T.M., "Orion Crew Module Aerodynamic Testing - Invited," $29^{\text {th }}$ AIAA Applied Aerodynamics Conference, Honolulu, HI, 27-30 June 2011, American Institute of Aeronautics and Astronautics, Reston, VA (submitted for publication)

${ }^{8}$ Owens, D.B. and Aubuchon, V.V., "Overview of Orion Crew Module and Launch Abort Vehicle Dynamic Stability," $29^{\text {th }}$ AIAA Applied Aerodynamics Conference, Honolulu, HI, 27-30 June 2011, American Institute of Aeronautics and Astronautics, Reston, VA (submitted for publication)

${ }^{9}$ Becker, J., Johnson, S., and Yechout, T.R., "Investigation of NASA Orion Wake Effects on Drogue Chute Aerodynamic Characteristics," AIAA 2011-2539, May 2011.

${ }^{10}$ Owens, D.B., Brandon, J.M., Croom, M.A., Fremaux, C.M., Heim, E.H., Vicroy, D.D., “Overview of Dynamic Test Techniques for Flight Dynamics Research and NASA LaRC,” AIAA-2006-3146, June 2006. 